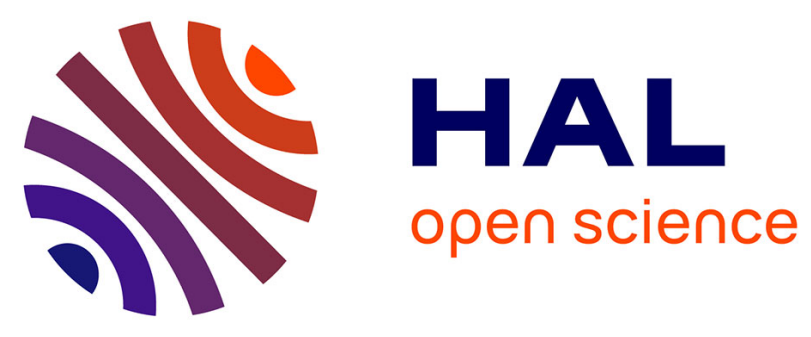

\title{
A 2-D Exact Subdomain Technique in Switched Reluctance Machines Taking Into Account of Finite Soft-Magnetic Material Permeability
}

Mohammed Yahia, Lazhar Roubache, Zakarya Khedda, Kamel Boughrara, Frédéric Dubas, Rachid Ibtiouen

\section{To cite this version:}

Mohammed Yahia, Lazhar Roubache, Zakarya Khedda, Kamel Boughrara, Frédéric Dubas, et al.. A 2-D Exact Subdomain Technique in Switched Reluctance Machines Taking Into Account of Finite SoftMagnetic Material Permeability. International Conference on Electrical Sciences and Technologies in Maghreb, Oct 2018, Alger, Algeria. hal-02130091

\section{HAL Id: hal-02130091 https://hal.science/hal-02130091}

Submitted on 15 May 2019

HAL is a multi-disciplinary open access archive for the deposit and dissemination of scientific research documents, whether they are published or not. The documents may come from teaching and research institutions in France or abroad, or from public or private research centers.
L'archive ouverte pluridisciplinaire HAL, est destinée au dépôt et à la diffusion de documents scientifiques de niveau recherche, publiés ou non, émanant des établissements d'enseignement et de recherche français ou étrangers, des laboratoires publics ou privés. 


\section{A 2-D Exact Subdomain Technique in Switched Reluctance Machines Taking Into Account of Finite Soft-Magnetic Material Permeability}

\author{
Mohammed BEN YAHIA \\ Laboratoire de Recherche en \\ Electrotechnique (LRE) \\ Ecole Nationale Polytechique (ENP) \\ El-Harrach, Algérie \\ mohammed.ben_yahia @g.enp.edu.dz \\ Kamel BOUGHRARA \\ Laboratoire de Recherche en \\ Electrotechnique (LRE) \\ Ecole Nationale Polytechique (ENP) \\ El-Harrach, Algérie \\ kamel.boughrara@g.enp.edu.dz
}

\author{
Lazhar ROUBACHE \\ Laboratoire de Recherche en \\ Electrotechnique (LRE) \\ Ecole Nationale Polytechique (ENP) \\ El-Harrach, Algérie \\ lazhar.roubache@g.enp.edu.dz \\ Frédéric DUBAS \\ Département ÉNERGIE, FEMTO-ST, \\ CNRS \\ Univ. Bourgogne Franche-Comté \\ F90000 Belfort, France \\ FDubas@gmail.com
}

\author{
Zakarya DJELLOUL-KHEDDA \\ LESI Laboratory \\ Univ. Djilali Bounaama Khemis Miliana \\ Khemis Miliana, Algérie \\ zakaryadoc@hotmail.com \\ Rachid IBTIOUEN \\ Laboratoire de Recherche en \\ Electrotechnique (LRE) \\ Ecole Nationale Polytechique (ENP) \\ El-Harrach, Algérie \\ rachid.ibtiouen@gmail.com
}

\begin{abstract}
This paper presents a two-dimensional (2-D) exact subdomain technique in polar coordinates considering the iron relative permeability in $6 / 4$ conventional switched reluctance machine (SRM) supplied by sinusoidal waveform of current. The general solutions of magnetic vector potential are obtained by applying the interfaces conditions (ICs) in both directions (i.e., $r$ - and $\theta$-edge ICs). The magnetic field is used to predict the iron core losses by using an analytical approach based on the Bertotti's model and the flux variation locus (FVL). Finally, the electromagnetic performances results have been performed and compared with the 2D finite-element (FE) method (FEM). The comparisons with FEM show good results of the proposed approach.
\end{abstract}

Keywords-Bertotti's model; electromagnetic performances; finite iron relative permeability; flux variation locus; switched reluctance machine; subdomain technique

\section{INTRODUCTION}

Benefiting from advantages of a simple mechanical structure, robust, high-thermal capability and high-speed potential [1]-[3]. SRM is receiving renewed attention as a viable candidate for various adjustable speed and high-torque applications such as in the automotive and traction [4]-[8].

In the interest for design and optimization of electrical machines, there is various modeling methods (viz., numerical, analytical and semi-analytical method), the first step to them is the reckoning of magnetic field. At present, subdomain technique is one of the most used semi-analytic method, which combines the very accurate electromagnetic performances calculation with a reduced computation time compared to numerical methods. In these models, the magnetic field solutions are based on the formal resolution of Maxwell's equations applied in subdomain by using the Fourier's series and the separation of variables method. Considering iron parts (i.e., the global or/and local saturation effect) is seldom investigated in the literature [9]-[11]. Dubas et al. (2017) [12]-[13] developed a first 2-D exact subdomain technique in Cartesian and polar coordinates considering finite soft-magnetic material permeability, which has been applied to an air- or iron-cored coil supplied by a constant current. The subdomains connection is performed directly in both directions. The general solutions of Maxwell's equations are deduced by applying the principle of superposition by respecting the boundary conditions (BCs) on the various edges. Recently, this novel scientific contribution has been implemented for radial-flux electrical machines [14]. For the same reason, another technique based on subdomain technique and Taylor polynomial has been applied in spoke-type permanent-magnet synchronous machines [15]-[16]. In this paper, which takes the magnetic field solution in the slots/teeth into account, the Dubas's approach in polar coordinates has been applied to 6/4 conventional SRM supplied by sinusoidal waveform of current. All results obtained with the semi-analytical model have been compared with those obtained by the 2-D FEM [17].

After the calculation of spatio-temporal magnetic field, an analytical method to calculate the iron core losses generated by these magnetic field variations is presented. Although there are several approaches for the iron loss calculation, the commonly accepted is based on the Bertotti's decomposition [18]. This approach can be implemented either in the post-processing step or in the non-linear resolution of a time stepping FE analysis [19]-[20]. Since the magnetic field waveforms in the SRMs are non-sinusoidal, the iron core losses are calculated by dividing the core of the machine in different parts and by using FVL method because the core loss is affected by the rotational flux [21]. Finally, all the results from the proposed semi-analytical model are validated by the linear FEM.

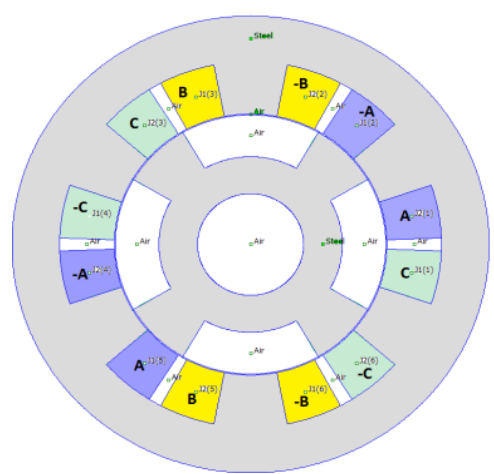

Fig. 1. Studied 6/4 conventional SRM.

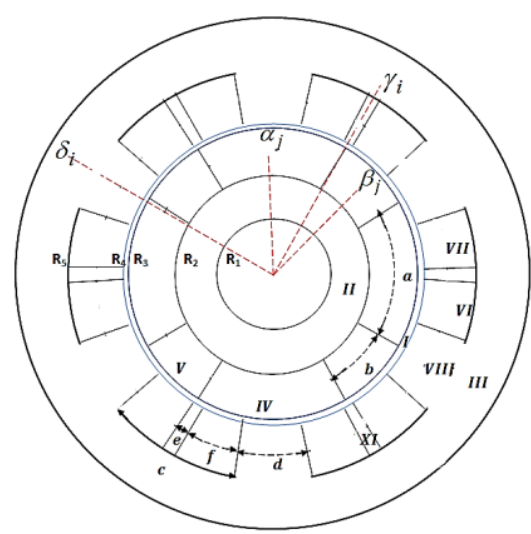

Fig. 2. Simplified model of SRM. 


\section{STUdied MACHINE AND MAGNETiC FiELD Solutions}

\section{A. Motor Geometry and Assumptions}

The conventional SRM [see Fig. 1] has 6 stator slots, 4 rotor slots, and 3 phases double layer concentrated winding. This machine has been partitioned into 9 regions as shown on Fig. 2, viz.

- Region I the air-gap;

- Region II and III respectively the rotor yoke (i.e., between rotor shaft and rotor slots/teeth) and the stator yoke;

- Region IV the rotor slots;

- Region V the rotor teeth;

- Region VI and VII respectively the stator slots of first layer (i.e., right in the slot), and of second layer (i.e., left in the slot);

- Region VIII the stator teeth;

- Region XI the non-periodic air-gap (i.e., between the two layer winding of stator slots).

The model is formulated in magnetic vector potential and in 2-D polar coordinates with the following assumptions:

- The end-effects are neglected, i.e., $\boldsymbol{A}=\left\{0 ; 0 ; A_{z}\right\}$;

- The eddy-current effects in the materials are neglected;

- The current density in the stator slots has only one component along the z-axis, i.e., $\boldsymbol{J}=\left\{0 ; 0 ; J_{z}\right\}$;

- The magnetic materials are considered as isotropic with constant magnetic permeability corresponding to linear zone of the $B(H)$ curve;

- The stator and rotor slots/teeth have radial sides.

B. General Solution with Non-homogeneous Neumann BCs

Magnetic vector potential $\boldsymbol{A}$ is calculated analytically with solving Poisson's or Laplace's equations with the separation of variables method, viz.,

$\Delta \boldsymbol{A}=0$ in Region I, II, III, IV, V, VIII and XI

$\Delta \boldsymbol{A}=-\mu_{0} \cdot \boldsymbol{J}$ in Region VI and VII

where $\mu_{0}$ is the vacuum permeability.

According to [13], the solutions of magnetic vector potential in all regions of conventional SRM are:

1) Air-gap subdomain (Region I): The solution of (1) in Region I, $r \in\left[R_{3} ; R_{4}\right]$ and $\forall \theta$, is defined by:

$$
\begin{aligned}
A_{z I}= & A_{10}+A_{20} \cdot \ln (r)+\sum_{n=1}^{\infty}\left[A_{1 n} \cdot\left(\frac{r}{R_{3}}\right)^{n}+A_{2 n} \cdot\left(\frac{r}{R_{2}}\right)^{-n}\right] \cdot \sin (n \theta) \\
& \cdots+\sum_{n=1}^{\infty}\left[A_{3 n} \cdot\left(\frac{r}{R_{3}}\right)^{n}+A_{4 n} \cdot\left(\frac{r}{R_{2}}\right)^{-n}\right] \cdot \cos (n \theta)
\end{aligned}
$$

where $n$ is a positive integer, and $\left\{A_{10} ; A_{20} ; A_{1 n} \sim A_{4 n}\right\}$ are the integration constants of Region I.

2) Stator and rotor yoke subdomain (Region II and III): In adding Dirichlet BC of the magnetic vector potential at $r=R_{1}$ and $r=R_{\text {ext }}$, viz., $\left.A_{z}(r, \theta)\right|_{r=R_{1} \vee r=R_{e t t}}=0 \quad \forall \theta$, the solution of (1) in Region II, $r \in\left[R_{1} ; R_{2}\right]$ and $\forall \theta$, can be written as:

$$
\begin{aligned}
A_{z I I}= & A_{50} \cdot \ln \left(\frac{r}{R_{1}}\right)+\sum_{n=1}^{\infty} A_{5 n} \cdot\left[\left(\frac{r}{R_{1}}\right)^{n}-\left(\frac{r}{R_{1}}\right)^{-n}\right] \cdot \sin (n \theta) \\
& \cdots+\sum_{n=1}^{\infty} A_{6 n} \cdot\left[\left(\frac{r}{R_{1}}\right)^{n}-\left(\frac{r}{R_{1}}\right)^{-n}\right] \cdot \cos (n \theta)
\end{aligned}
$$

where $\left\{A_{50} ; A_{5 n} ; A_{6 n}\right\}$ are the integration constants of Region II.

The solution of Region III, $r \in\left[R_{5} ; R_{\text {ext }}\right]$ and $\forall \theta$, is similar to (4) by replacing $\left\{A_{50} ; A_{5 n} ; A_{6 n}\right\}$ with $\left\{A_{70} ; A_{7 n} ; A_{8 n}\right\}$ and $R_{1}$ with $R_{e x t}$.

3) $i^{\text {th }}$ Stator slot subdomain (Region VI and VII): The solution of (2) in Region VI, $r \in\left[R_{4} ; R_{5}\right] \& \theta \in\left[\gamma_{1 i}-f / 2 ; \gamma_{1 i}+f / 2\right]$, is defined by:

$$
A_{z V I i}(r, \theta)=C_{1 i 0}+C_{2 i 0} \cdot \ln (r)-\frac{1}{4} \cdot \mu_{0} \cdot J 1(i)_{z} \cdot r^{2}
$$

where $m$ and $k$ are positive integers, $\gamma_{1 i}=\gamma_{i}-(e+f) / 2$ and $f$ are respectively the position and opening width of first layer winding in the $i^{\text {th }}$ stator slot, $\left\{C_{1 i 0} ; C_{2 i 0} ; C_{1 i m} ; C_{2 i m} ; C_{3 i k} ; C_{4 i k}\right\}$ are the integration constants of Region VI, $v_{m f}=m \pi / f$ and $\lambda_{k s}=k \pi / \ln \left(R_{5} / R_{4}\right)$ are respectively the periodicity of $A_{z}$ in $\theta$ and $r$-edges.

The solution of Region VII, $r \in\left[R_{4} ; R_{5}\right] \& \theta \in\left[\gamma_{2 i}-f / 2 ; \gamma_{2 i}+f / 2\right]$, is similar to (5) by replacing $\left\{C_{1 i 0} ; C_{2 i 0} ; C_{1 i m} ; C_{2 i m} ; C_{3 i k} ; C_{4 i k}\right\}$ with $\left\{C_{5 i 0} ; C_{6 i 0} ; C_{5 i m} ; C_{6 i m} ; C_{7 i k} ; C_{8 i k}\right\}, J 1(i)_{z}$ with $J 2(i)_{z}$, and $\gamma_{1 i}$ with $\gamma_{2 i}=\gamma_{i}+(e+f) / 2$.

4) $i^{\text {th }}$ Non-periodic air-gap and $i^{\text {th }}$ stator tooth subdomain (Region VIII and XI): The solution of (1) in Region VIII, $r \in\left[R_{4} ; R_{5}\right] \& \theta \in\left[\gamma_{i}-e / 2 ; \gamma_{i}+e / 2\right]$, and Region XI, $r \in\left[R_{4} ; R_{5}\right] \&$ $\theta \in\left[\delta_{i}-d / 2 ; \delta_{i}+d / 2\right]$, can be obtained directly from (5) with $J 1(i)_{z}=0$.

For Region VIII, $\left\{C_{1 i 0} ; C_{2 i 0} ; C_{1 i m} ; C_{2 i m} ; C_{3 i k} ; C_{4 i k}\right\}$ is replaced by $\left\{D_{1 i 0} ; D_{2 i 0} ; D_{1 i m} ; D_{2 i m} ; D_{3 i k} ; D_{4 i k}\right\}, \gamma_{1 i}$ by $\gamma_{i}, f$ by $e$, and $v_{m f}$ by $v_{m e}=m \pi / e$. 
For Region IX, $\left\{C_{1 i 0} ; C_{2 i 0} ; C_{1 i m} ; C_{2 i m} ; C_{3 i k} ; C_{4 i k}\right\}$ is replaced by $\left\{D_{5 i 0} ; D_{6 i 0} ; D_{5 i m} ; D_{6 i m} ; D_{7 i k} ; D_{8 i k}\right\}, \gamma_{1 i}$ by $\delta_{i}, f$ by $d$, and $v_{m f}$ by $v_{m d}=m \pi / d$.

5) $j^{\text {th }}$ Rotor slot and $j^{\text {th }}$ rotor tooth subdomain (Region IV and $V$ ): The solution of (1) in Region IV, $r \in\left[R_{2} ; R_{3}\right]$ \& $\theta \in\left[\alpha_{j}-a / 2 ; \alpha_{i}+a / 2\right]$, is defined by:

$$
\begin{aligned}
A_{z I V j}(r, \theta)= & B_{1 j 0}+B_{2 j 0} \cdot \ln (r) \\
& \cdots+\sum_{m=1}^{\infty}\left[\begin{array}{l}
B_{1 j m}\left(\frac{r}{R_{3}}\right)^{v_{m a}} \\
\left.\cdots+B_{2 j m}\left(\frac{r}{R_{2}}\right)^{-v_{m a}}\right] \cdot \cos \left[v_{m a} \cdot\left(\theta-\alpha_{j}+\frac{a}{2}\right)\right] \\
\cdots+\sum_{k=1}^{\infty}\left\{\begin{array}{l}
\left.B_{3 j k} \cdot \frac{\operatorname{sh}\left[\lambda_{k r} \cdot\left(\theta-\alpha_{j}+\frac{a}{2}\right)\right]}{\operatorname{sh}\left(\lambda_{k r} \cdot a\right)}\right] \cdot \operatorname{sh}\left[\lambda_{k r} \cdot\left(\theta-\alpha_{j}-\frac{a}{2}\right)\right] \\
\operatorname{sh}\left(\lambda_{k r} \cdot a\right)
\end{array}\right\} \cdot \sin \left[\lambda_{k r} \cdot \ln \left(\frac{r}{R_{2}}\right)\right]
\end{array}\right.
\end{aligned}
$$

where $\alpha_{j}$ and $a$ are respectively the position and opening width of $j^{\text {th }}$ rotor slot, $\left\{B_{1 j 0} ; B_{2 j 0} ; B_{1 j m} ; B_{2 j m} ; B_{3 j k} ; B_{4 j k}\right\}$ are the integration constants of Region IV, $v_{m a}=m \pi / a$ and $\lambda_{k r}=k \pi / \ln \left(R_{3} / R_{2}\right)$ are respectively the periodicity of $A_{z}$ in $\theta$ and $r$-edges.

The solution of Region V, $r \in\left[R_{2} ; R_{3}\right] \& \theta \in\left[\beta_{j}-b / 2 ; \beta_{i}+b / 2\right]$, is similar to (6) by replacing $\left\{B_{1 j 0} ; B_{2 j 0} ; B_{1 j m} ; B_{2 j m} ; B_{3 j k} ; B_{4 j k}\right\}$ with $\left\{B_{5 j 0} ; B_{6 j 0} ; B_{5 j m} ; B_{6 j m} ; B_{7 j k} ; B_{8 j k}\right\}, a$ with $b$, and $\alpha_{j}$ with $\beta_{j}$.

\section{Magnetic Flux Density}

The field vectors $\boldsymbol{B}=\left\{B_{r} ; B_{\theta} ; 0\right\}$ and $\boldsymbol{H}=\left\{H_{r} ; H_{\theta} ; 0\right\}$ are coupled by the magnetic material equation:

$$
\begin{aligned}
& \boldsymbol{B}=\mu_{0} \cdot \boldsymbol{H} \text { in Region I, IV, VI, VII and XI } \\
& \boldsymbol{B}=\mu_{0} \cdot \mu_{r c} \cdot \boldsymbol{H} \text { in Region II, III, V and VII }
\end{aligned}
$$

where $\mu_{r c}$ is the relative recoil permeability of iron parts.

Using $\boldsymbol{B}=\nabla \times \boldsymbol{A}$, the components of $\boldsymbol{B}$ can be deduced by

$$
B_{r}=\frac{1}{r} \cdot \frac{\partial A_{z}}{\partial \theta} \& B_{\theta}=-\frac{\partial A_{z}}{\partial r}
$$

\section{Stator Current Density Source}

The stator current densities in the stator slots for double layer concentrated winding are defined as [11]:

$$
J 1(i)=\frac{N_{c}}{S} \cdot C_{(1)}^{T} \cdot i_{g} \& J 2(i)=\frac{N_{c}}{S} \cdot C_{(2)}^{T} \cdot i_{g}
$$

where $i_{g}=\left[\begin{array}{lll}i_{a} & i_{b} & i_{c}\end{array}\right]$ is the vector of phase currents, $S=f \cdot\left(R_{5}{ }^{2}-R_{4}{ }^{2}\right) / 2$ is the surface of the stator slot coil, and $C_{(1)}^{T} \& C_{(2)}^{T}$ are the transpose of the connecting matrix between the 3-phases current and the stator slots that represent the distribution of stator windings in the slots of the $6 / 4$ conventional SRM with double layer winding is given by [11]

$$
C_{(1)}^{T}=\left[\begin{array}{cccccc}
-1 & 0 & 0 & 1 & 0 & 0 \\
0 & 1 & 0 & 0 & -1 & 0 \\
0 & 0 & -1 & 0 & 0 & 1
\end{array}\right] \& C_{(2)}^{T}=\left[\begin{array}{cccccc}
0 & 0 & -1 & 0 & 0 & 1 \\
-1 & 0 & 0 & 1 & 0 & 0 \\
0 & 1 & 0 & 0 & -1 & 0
\end{array}\right]
$$

These connection matrices can be generated automatically by using ANFRACTUS TOOL developed in [22].

\section{E. Boundary Conditions}

The conventional SRM [see Fig. 2] made up of 9 regions, The ICs in this model can be divided into two types. One is over angle interval for given radius value $\left\{R_{2} ; R_{3} ; R_{4} ; R_{5}\right\}$ (i.e., $\theta$-edges ICs) and the other is over radius interval for given angle $\left\{\alpha_{j} \pm a / 2 ; \beta_{j} \pm b / 2 ; \gamma_{i} \pm c / 2 ; \delta_{i} \pm d / 2 ; \gamma_{i} \pm e / 2\right\}$ (i.e., $r$-edges ICs).

We obtain on the

- $\theta$-edges ICs:

- The ICs between Region II, IV and V at $r=R_{2}$ as:

$A_{z I I}\left(R_{2}, \theta\right)=A_{z I V j}\left(R_{2}, \theta\right)$ for $\theta \in\left[\alpha_{j}-a / 2, \alpha_{j}+a / 2\right]$

$A_{z I I}\left(R_{2}, \theta\right)=A_{z V j}\left(R_{2}, \theta\right)$ for $\theta \in\left[\beta_{j}-b / 2, \beta_{j}+b / 2\right]$

$H_{\theta I I}\left(R_{2}, \theta\right)=H_{\theta I V j}\left(R_{2}, \theta\right)$ for $\theta \in\left[\alpha_{j}-a / 2, \alpha_{j}+a / 2\right]$

$H_{\theta I I}\left(R_{2}, \theta\right)=H_{\theta V j}\left(R_{2}, \theta\right)$ for $\theta \in\left[\beta_{j}-b / 2, \beta_{j}+b / 2\right]$

- The ICs between Region I, IV and V at $r=R_{3}$ are similar to $(14) \sim(17)$ by replacing II with I and $R_{2}$ with $R_{3}$.

- $\quad$ The ICs between Region I, VI, VII, VIII and XI at $r=R_{4}$ as:

$A_{z I}\left(R_{4}, \theta\right)=A_{z V I i}\left(R_{4}, \theta\right)$ for $\theta \in\left[\gamma_{i}-c / 2, \gamma_{i}-c / 2+f\right]$

$A_{z I}\left(R_{4}, \theta\right)=A_{z V I I i}\left(R_{4}, \theta\right)$ for $\theta \in\left[\gamma_{i}+c / 2-f, \gamma_{i}+c / 2\right]$

$A_{z I}\left(R_{4}, \theta\right)=A_{z V I I I}\left(R_{4}, \theta\right)$ for $\theta \in\left[\delta_{i}-d / 2, \delta_{i}+d / 2\right]$

$A_{z I}\left(R_{4}, \theta\right)=A_{z X I i}\left(R_{4}, \theta\right)$ for $\theta \in\left[\gamma_{i}-e / 2, \gamma_{i}+e / 2\right]$

$H_{\theta I}\left(R_{4}, \theta\right)=H_{\theta V I i}\left(R_{4}, \theta\right)$ for $\theta \in\left[\gamma_{i}-c / 2, \gamma_{i}-c / 2+f\right]$

$H_{\theta I}\left(R_{4}, \theta\right)=H_{\theta V I I i}\left(R_{4}, \theta\right)$ for $\theta \in\left[\gamma_{i}+c / 2-f, \gamma_{i}+c / 2\right]$

$H_{\theta I}\left(R_{4}, \theta\right)=H_{\theta V I I I i}\left(R_{4}, \theta\right)$ for $\theta \in\left[\delta_{i}-d / 2, \delta_{i}+d / 2\right]$

$H_{\theta I}\left(R_{4}, \theta\right)=H_{\theta X I i}\left(R_{4}, \theta\right)$ for $\theta \in\left[\gamma_{i}-e / 2, \gamma_{i}+e / 2\right]$

- $\quad$ The ICs between Region III, VI, VII, VIII and XI at $r=R_{5}$ are similar to (16) $\sim(\mathbf{2 5})$ by replacing I with III and $R_{4}$ with $R_{5}$.

- $r$-edges ICs:

- The ICs between Region IV and V at $\alpha_{j}+a / 2=\beta_{j}-b / 2$ and $\alpha_{j+1}-a / 2=\beta_{j}+b / 2$ for $r \in\left[R_{2} ; R_{3}\right]$ :

$$
\begin{aligned}
& A_{z I V j}\left(r, \alpha_{j}+a / 2\right)=A_{z V j}\left(r, \beta_{j}-b / 2\right) \\
& H_{r I V j}\left(r, \alpha_{j}+a / 2\right)=H_{r V j}\left(r, \beta_{j}-b / 2\right) \\
& A_{z I V(j+1)}\left(r, \alpha_{j+1}-a / 2\right)=A_{z V j}\left(r, \beta_{j}+b / 2\right) \\
& H_{r I V(j+1)}\left(r, \alpha_{j+1}-a / 2\right)=H_{r V j}\left(r, \beta_{j}+b / 2\right)
\end{aligned}
$$


TABLE I

PARAMETERS OF 6/4 CONVENTIONAL SRM

\begin{tabular}{ccc}
\hline \hline Symbol & Parameter & Value and unit \\
\hline$Q_{s}$ & Number of stator slots & 6 \\
$Q_{r}$ & Number of rotor poles & 4 \\
$R_{2}$ & Internal radius of rotor slot & $17.3 \mathrm{~mm}$ \\
$R_{5}$ & External radius of stator slot & $36 \mathrm{~mm}$ \\
$R_{e x t}$ & Radius of the external stator surface & $45 \mathrm{~mm}$ \\
$R_{4}$ & Radius of the stator internal surface & $25.7 \mathrm{~mm}$ \\
$R_{3}$ & Radius of the rotor surface & $25.5 \mathrm{~mm}$ \\
$g$ & Air-gap length & $0.2 \mathrm{~mm}$ \\
$L_{u}$ & Stack length & $60 \mathrm{~mm}$ \\
$R_{1}$ & Radius of the shaft & $10 \mathrm{~mm}$ \\
$a$ & Rotor slot opening & $60^{\circ}$ \\
$b$ & Rotor tooth opening & $30^{\circ}$ \\
$c$ & Stator slot opening & $38^{\circ}$ \\
$d$ & Stator tooth opening & $22^{\circ}$ \\
$e$ & Non-periodic air-gap (i.e., between the two & $4^{\circ}$ \\
$f$ & layer winding of stator slots) opening & $17^{\circ}$ \\
$I_{n}$ & Opening of a slot coil & $15 \mathrm{~A}$ \\
$N_{c}$ & Rated phase current & 20 \\
$N$ & Number of conductor of slot coil & $1,500 \mathrm{rpm}$ \\
\hline \hline
\end{tabular}

- The ICs between Region VII and VIII at $\gamma_{i}+c / 2=\delta_{i}-d / 2$ and between Region VI and VIII at $\gamma_{i+1}-c / 2=\delta_{i}+d / 2$ for $r \in\left[R_{4} ; R_{5}\right]$ :

$$
\begin{aligned}
& A_{z V I I i}\left(r, \gamma_{i}+c / 2\right)=A_{z V I I I i}\left(r, \delta_{i}-d / 2\right) \\
& H_{r V I I i}\left(r, \gamma_{i}+c / 2\right)=H_{r V I I I i}\left(r, \delta_{i}-d / 2\right) \\
& A_{z V I(i+1)}\left(r, \gamma_{i+1}-c / 2\right)=A_{z V I I I i}\left(r, \delta_{i}+d / 2\right) \\
& H_{r V I(i+1)}\left(r, \gamma_{i+1}-c / 2\right)=H_{r V I I I i}\left(r, \delta_{i}+d / 2\right)
\end{aligned}
$$

- The ICs between Region VI and XI at $\gamma_{i}-e / 2=\gamma_{i}-c / 2+f$ and between Region VII and XI at $\gamma_{i}+e / 2=\gamma_{i}+c / 2-f$ for $r \in\left[R_{4} ; R_{5}\right]$ :

$A_{z V I i}\left(r, \gamma_{i}-c / 2+f\right)=A_{z X I i}\left(r, \gamma_{i}-e / 2\right)$

$H_{r V I i}\left(r, \gamma_{i}-c / 2+f\right)=H_{r X I i}\left(r, \gamma_{i}-e / 2\right)$

$A_{z V I I i}\left(r, \gamma_{i}+c / 2-f\right)=A_{z X I i}\left(r, \gamma_{i}+e / 2\right)$

$H_{r V I I i}\left(r, \gamma_{i}+c / 2-f\right)=H_{r X I i}\left(r, \gamma_{i}+e / 2\right)$

The system of $36 \mathrm{BCs}$ matrix equations (12) to (35) is used to determine the coefficients of magnetic vector potentials in the 9 regions of the conventional SRM.

\section{RESUlTS AND VALIDATIONS}

The 2-D semi-analytical model considering finite softmagnetic material permeability is used to determine the electromagnetic performances of conventional SRM. The main parameters of the studied machine are given in Table I. The results of semi-analytic model are verified by 2-D linear FEM. The waveforms of $r$ - and $\theta$-components of the magnetic flux density in the various regions are computed with a finite number of harmonic terms, viz., $N=200$ and $M=K=40$ (in periodic and non-periodic region respectively). The analytic calculation of magnetic flux distribution in all regions is done considering the same relative permeability in all iron parts (i.e., stator/rotor yoke and teeth). However, it is possible to use a different relative permeability value for each region.

For an initial rotor position at $\alpha(1)=\gamma(1)=0$ [see Fig. 2] with a current equal to $I(i)=-I_{n} \cdot \cos [(i-1) \cdot 2 \pi / m]$.

In Fig. 3, a comparison between the numerical results and semi-analytical predictions is shown in term of the $r$ - and $\theta$ component magnetic flux density in the middle of the air-gap (i.e., Region I). The simulations are done for two different values of iron core relative permeability (viz., 100 and 800). Fig. 4 shows the magnitude of $\boldsymbol{B}$ in all machines regions for $\mu_{r}=100$. For full-load condition (viz., 15 A @ 1,500 rpm with $\left.\theta_{r s 0}=\pi / Q_{r}\right)$, the electromagnetic torque is presented in Fig. 5 . The induced magnetic flux linkage per phase is given in Figs. 6. Fig. 7 shows self- and mutual-inductance of the machine. It can be seen that the proposed semi-analytical model gives good results compared to the numerical method.

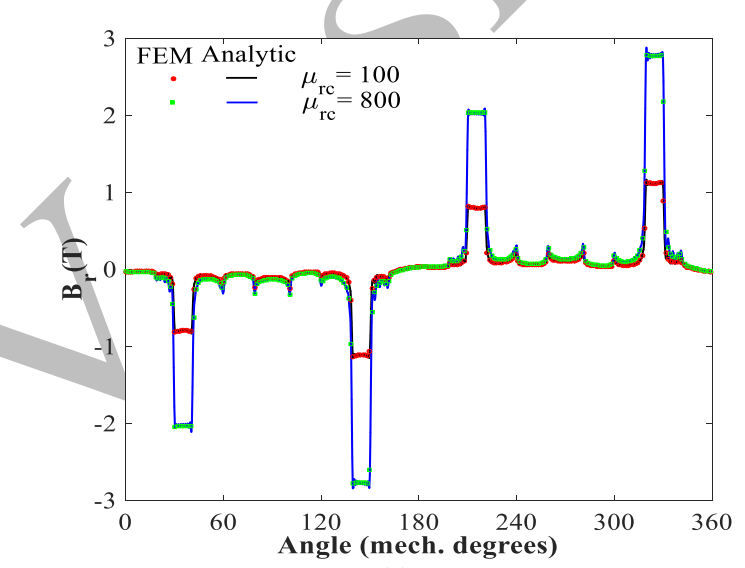

(a)

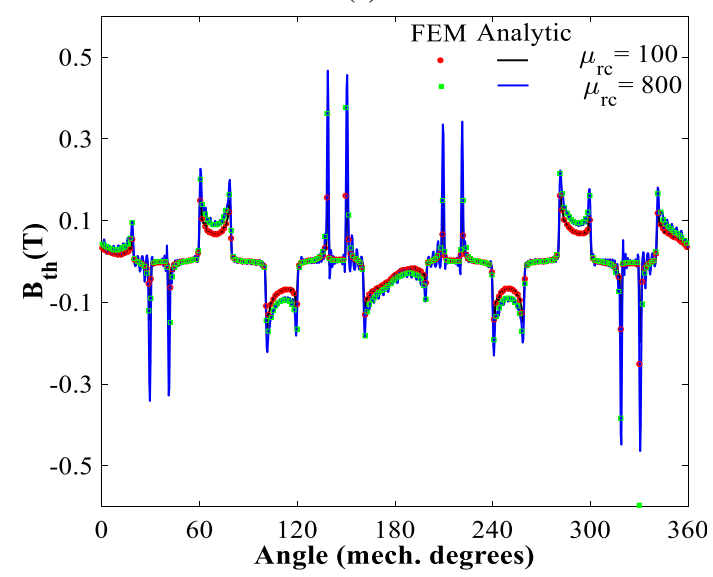

(b)

Fig. 3. Waveform of the magnetic flux density in the middle of the air-gap (i.e., Region I): (a) $r$ - and (b) $\theta$-component.

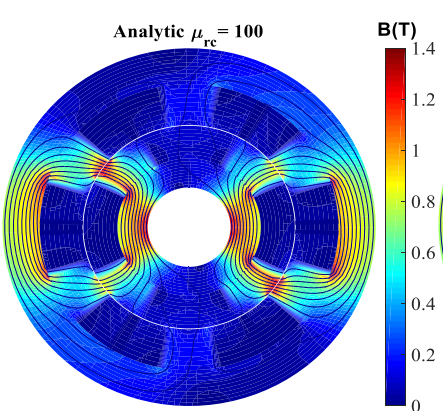

(a)

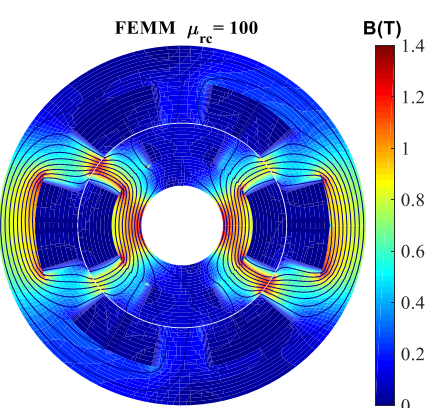

(b)
Fig. 4. Flux density inside the machine: (a) analytic and (b) FEM 


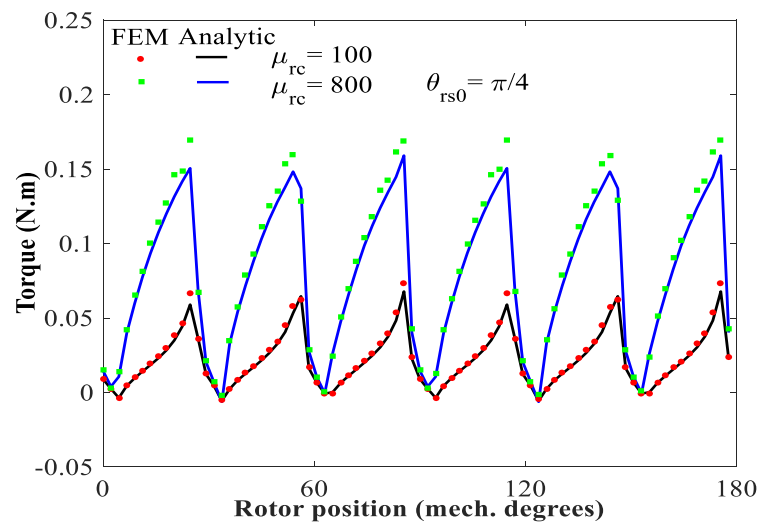

Fig. 5. Waveform of the electromagnetic torque (for full-load condition).

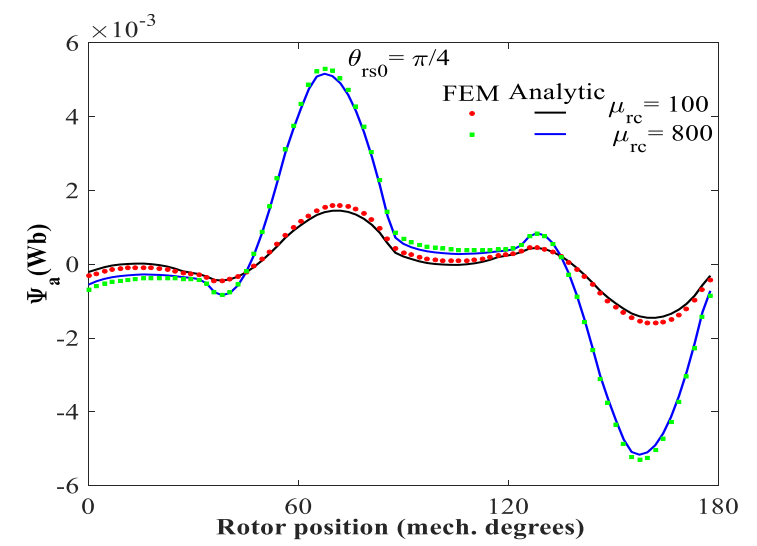

Fig. 6. Waveform of the magnetic flux linkage for full-load condition (10A@1,500 rpm) with $\theta_{r s 0}=\pi / 4$.

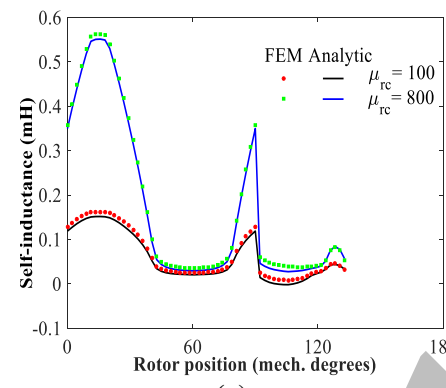

(a)

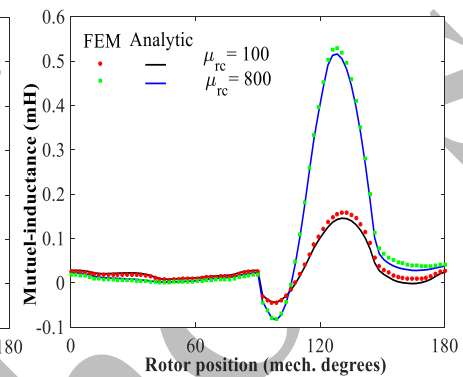

(b)
Fig. 7. Waveform of the (a) self- and (b) mutual-inductance.

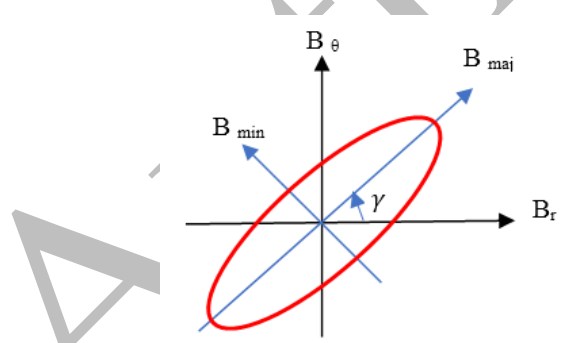

Fig. 8. Elliptical locus for the iron loss evaluation.

TABLE II

IRON LOSS COEFFICIENTS M270-35A

\begin{tabular}{lll}
\hline \hline Symbols & Parameters & Values (Units) \\
\hline$k_{\text {hys }}$ & Hysteresis losses coefficient & $130.24 \mathrm{~W} \cdot \mathrm{s} \cdot \mathrm{T}^{-\alpha} \cdot \mathrm{m}^{-3}$ \\
$k_{\text {ex }}$ & Excess loss coefficient & $3.57 \mathrm{E}-1 \mathrm{~W} \cdot \mathrm{s}^{1.5} \cdot \mathrm{T}^{-1.5} \cdot \mathrm{m}^{-3}$ \\
$\alpha$ & Steinmetz constant & 2 \\
$\sigma$ & Electrical conductivity & $1.92 \mathrm{E} 6 \mathrm{~S} \cdot \mathrm{m}^{-1}$ \\
$d_{\mathbb{D}}$ & Lamination thickness & $0.35 \mathrm{~mm}$ \\
\hline \hline
\end{tabular}

\section{IRON CORE LOSS COMPUTATION}

\section{A. Introduction}

The analysis technique to predict the iron core loss generated in a SRM by magnetic field becomes very important in the machine design. For a no-sinusoidal excitation and considering laminations, Berttotti developed a model that divides the losses into three components [18]:

$$
P_{\text {iron }}=\underbrace{k_{\text {hys }} f\left(B_{m}\right)^{\alpha}}_{P_{\text {hys }}}+\underbrace{\frac{d_{l} f \sigma}{12} \int_{0}^{T}\left(\frac{d B(t)}{d t}\right)^{2} d t}_{P_{\text {edd }}}+\underbrace{k_{e x} f \int_{0}^{T}\left|\frac{d B(t)}{d t}\right| d t}_{P_{\text {ex }}}
$$

where $P_{h y s}, P_{e d d}$ and $P_{e x}$ are respectively the hysteresis, eddycurrent and excess losses; $B_{m}$ is the peak value of the magnetic flux density in the iron core; and $T=1 / f$ is the iron core magnetic flux density period with $f$ the frequency. The loss coefficients are given in Table II.

\section{B. Flux Variation Locus Method}

The iron core losses are affected by the alternating flux, but also by the rotational flux. It is useful to use the FVL method where the rotational flux effect can be taken into account [19][21]. The universal locus of the flux in rotating machines is elliptical, as shown in Fig. 8, where $B_{m a j}$ and $B_{\text {min }}$ are respectively the major and minor axis component of magnetic flux density. The algorithm to calculate $B_{m a j}$ and $B_{\text {min }}$, which can be determined from $\left\{B_{r} ; B_{\theta}\right\}$, is represented [21].

The iron core losses are calculated by taken into account the rotational flux effect in the 6/4 conventional SRM in different areas $S_{n_{p}}$ where $n_{p}=1, \ldots, N_{p}$ from the magnetic flux density where (36) are extended to

$$
\begin{aligned}
& P_{h y s}=k_{h y s} f \cdot \sum_{n_{p}=1}^{N_{p}} V_{n_{p}}\left(B_{m a j, n_{p}}{ }^{\alpha}+B_{m i n, n_{p}}{ }^{\alpha}\right) \\
& P_{\text {edd }}=\frac{d_{l} f \sigma}{12} \cdot \sum_{n_{p}=1}^{N_{p}} V_{n_{p}} \int_{0}^{T}\left[\left(\frac{d B_{m a j, n_{p}}(t)}{d t}\right)^{2}+\left(\frac{d B_{\text {min, } n_{p}}(t)}{d t}\right)^{2}\right] d t \\
& P_{e x}=k_{e x} f \cdot \sum_{n_{p}=1}^{N_{p}} V_{n_{p}} \int_{0}^{T}\left[\left(\frac{d B_{\text {maj }, n_{p}}(t)}{d t}\right)^{2}+\left(\frac{d B_{\text {min, } n_{p}}(t)}{d t}\right)^{2}\right]^{\frac{3}{4}} d t
\end{aligned}
$$

where $V_{n_{p}}=S_{n_{p}} \cdot L_{u}$ are the different volume in the iron.

\section{Iron Core Loss Validation by the FEM}

The iron core losses are calculated for $I=\{4 ; 8 ; 14\} A$ with the rotor speed varying from 750 to 3,000 rpm. Fig. 9 present the influence of rotor speed variation on the hysteresis, eddy-current and excess losses in the stator and rotor. Obviously the analytical results are agrees well with the FEM. In Fig. 10, the iron core losses evolutions in the rotor and stator with respect to rotor speed for two different values of iron core relative permeability are illustrated. Fig. 11(a) shows the iron core losses according to the field current with three rotor speed (viz., 176, 175 and 3,000 rpm). The iron core losses increases with the increase in field current. Moreover, in Fig. 11(b) which are the function of rotor sped in three different supply current. A good agreement is seen between the analytically obtained and the FEM results. 


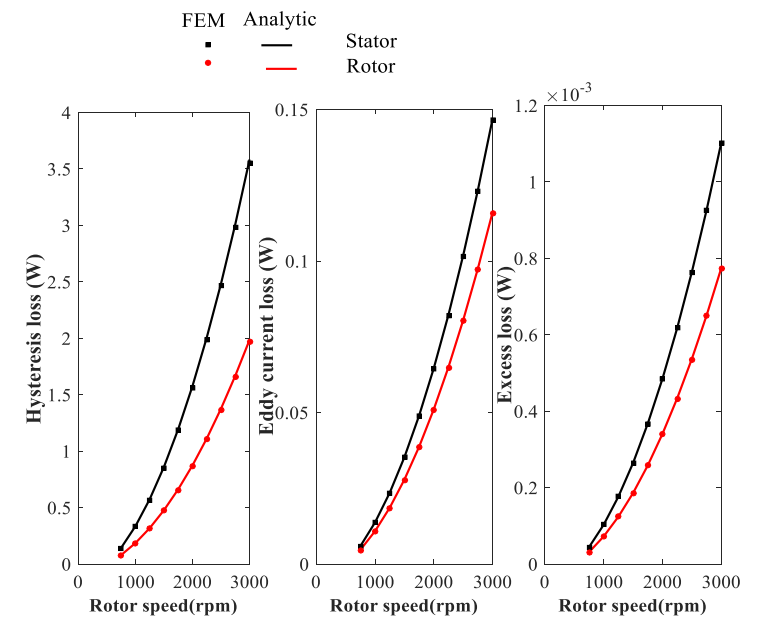

Fig. 9. On-load analytically and FEM predicted iron losses: Hysteresis, eddy-current and excess losses in the rotor and stator.

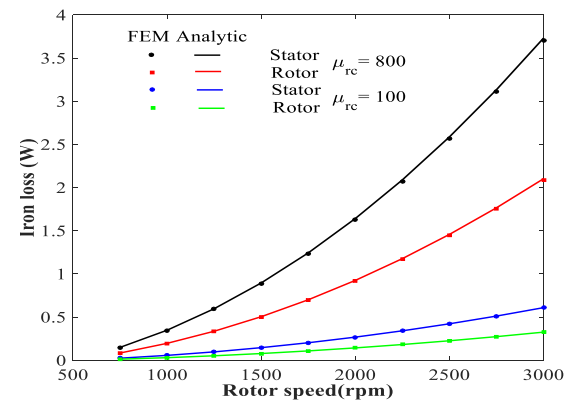

Fig. 10. Iron loss evolution for full-load condition in the stator and rotor for two different values of iron core relative permeability (viz., 100 and 800).

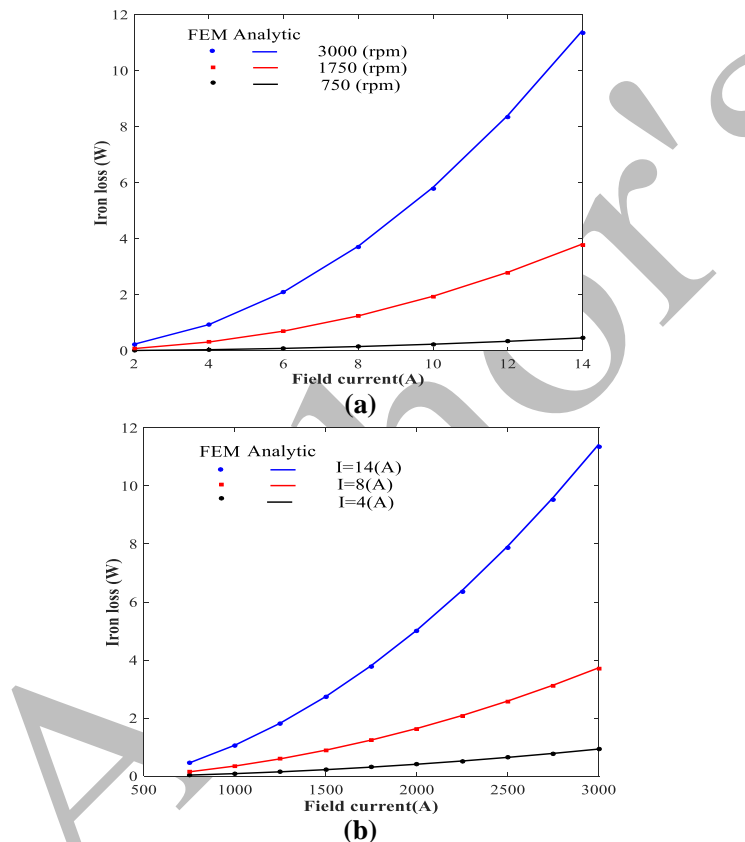

(b)

Fig. 11. Iron core loss evolution according to: (a) field current and (b) rotor speed.

\section{CONCLUSION}

In this paper, we have applied a new exact semi-analytical model based on the 2-D subdomain technique in polar coordinates [13]-[14] to predict the electromagnetic performances in SRM for any rotor positions. It has the ability in any number of stator slots, rotor poles and phases and for different type of stator winding. Currently, in this paper, we chose to present only the 6/4 conventional SRM with 3phases. Because the SRMs always operate with certain saturation, the proposed model takes into account of the finite value of relative permeability in all machine. It can be considered as a viable alternative to FEM for analysis of SRMs. The Bertotti's model and the FVL method are used to predict the iron core losses in different parts of machine. The results confirmed the accuracy of the proposed model.

\section{REFERENCES}

[1] N. Radimov, N. Ben-Hail, and R. Rabinovici, "Switched reluctance machines as three-phase AC autonomous generator," IEEE Trans. Magn., vol. 42, no. 11, pp. 3760-3764, Nov. 2006.

[2] H. Cheng, H. Chen, and Z. Yang, "Design indicators and structure optimisation of switched reluctance machine for electric vehicles," IET Elect. Power Appl., vol. 9, no 4, pp. 319-331, Apr. 2015.

[3] M. Takeno, A. Chiba, N. Hoshi, S. Ogasawara, M. Takemoto and A. Rahman, "Test results and torque improvement of the $50-\mathrm{kW}$ switched reluctance motor designed for hybrid electric vehicles," IEEE Trans. Ind. Appl., vol. 48, no. 4, pp. 1327-1334, Jul.-Aug. 2012.

[4] G.J. Li, J. Ojeda, S. Hlioui, E. Hoang, M. Lecrivain and M. Gabsi, "Modification in rotor pole geometry of mutually coupled switched reluctance machine for torque ripple mitigating," IEEE Trans. Magn., vol. 48, no. 6, pp. 2025-2034, Jun. 2012.

[5] P.J. Lawrenson, J.M. Stephenson, P.T, Blenkinsop, J. Korda, and N.N. Fulton, "Variable-speed switched reluctance motors," IEE Proceedings B - Electric Power Applications, vol. 127, no. 4, pp. 253-265, Jul. 1980.

[6] C. Sahin, A.E. Amac, M. Karacor, and A. Emadi, "Reducing torque ripple of switched reluctance machines by relocation of rotor moulding clinches," IET Elect. Power Appl., vol. 6, no. 9, pp. 753-760, Nov. 2012.

[7] C. Lin and B. Fahimi, "Prediction of acoustic noise in switched reluctance motor drives," IEEE Trans. Energy Convers., vol. 29, no 1, pp. 250-258, Mar. 2014.

[8] D.H. Lee, T.H. Pham, and J.W. Ahn, "Design and operation characteristics of four-two pole high-speed SRM for torque ripple reduction," IEEE Trans. Ind. Elec., vol. 60, no 9, pp. 3637-3643, Sep. 2013.

[9] R.L.J. Sprangers, J.J.H. Paulides, B.L.J. Gysen, J. Waarma, and E.A Lomonova, "Semi-analytical framework for synchronous reluctance motor analysis including finite soft-magnetic material permeability," IEEE Trans. Magn., vol. 51, no. 11, Nov. 2015, Art. ID 8110504.

[10] K.Z. Djelloul, K. Boughrara, R. Ibtiouen, and F. Dubas, "Nonlinear analytical calculation of magnetic field and torque of switched reluctance machines," in Proc. CISTEM, Marrakech, Morocco, Oct. 26-28, 2016.

[11] K.Z. Djelloul, K. Boughrara, F. Dubas, and R. Ibtiouen, "Nonlinear analytical prediction of magnetic field and electromagnetic performances in switched reluctance machines," IEEE Trans. Magn., vol. 53, no. 7, Jul. 2017, Art. ID 8107311.

[12] F. Dubas, and K. Boughrara, "New scientific contribution on the 2-D subdomain technique in Cartesian coordinates: Taking into account of iron parts," Math. Comput. Appl., vol. 22, no. 1, p. 17, Feb. 2017, DOI: $10.3390 /$ mca22010017.

[13] F. Dubas, and K. Boughrara, "New scientific contribution on the 2-D subdomain technique in polar coordinates: Taking into account of iron parts," Math. Comput. Appl., vol. 22, no. 4, p. 42, Oct. 2017, DOI: $10.3390 / \mathrm{mca} 22040042$.

[14] L. Roubache, K. Boughrara, F. Dubas, and R. Ibtiouen, "New subdomain technique for electromagnetic performances calculation in radial-flux electrical machines considering finite soft-magnetic material permeability," IEEE Trans. Magn., vol. 54, no. 4, Apr. 2018, Art. ID 8103315.

[15] L. Roubache, K. Boughrara, F. Dubas, and R. Ibtiouen, "Semi-analytical modeling of spoke-type permanent-magnet machines considering the iron core relative permeability: Subdomain Technique and Taylor polynomial," Prog. Electromagn. Res. B., vol. 77, pp. 85-101, Jul. 2017.

[16] L. Roubache, K. Boughrara, F. Dubas and R. Ibtiouen, "Semi-analytical modeling of spoke-type permanent-magnet machines considering nonlinear magnetic saturation: Subdomain Technique and Taylor polynomial," Math. and Comp. in Simul., under review.

[17] D.C. Meeker. (Apr. 1, 2009). Finite Element Method Magnetics ver. 4.2.

[18] G. Bertotti, "General properties of power losses in soft ferromagnetic materials," IEEE Trans. Magn., vol. 24, no. 1, pp. 621-630, Jan. 1988. 
[19] Y. Huang, J. Dong, J. Zhu, and Y. Guo, "Core loss modeling for permanent-magnet motor based on flux variation locus and finite-element method," IEEE Trans. Magn., vol. 48, no 2, pp. 1023-1026, Feb. 2012.

[20] L. Chen, H. Chen, and W Yan, "A fast iron loss calculation model for switched reluctance motors," IET Elect. Power Appl. vol. 11, no. 3, pp. 478-486, Mar. 2017.

[21] K.Z. Djelloul, K. Boughrara, F. Dubas, A. Kechroud and A. Tikellaline, "Analytical prediction of iron core losses in flux-modulated permanentmagnet synchronous machines," IEEE Trans. Magn., under review.

[22] D. Ouamara, F. Dubas, M.N. Benallal, S-A. Randi, and C. Espanet, "Automatic winding generation using matrix representation ANFRACTUS TOOL 1.0 -," Acta Polytechnica, vol. 58, no. 01, pp. 3746, Mar. 2018, DOI: 10.14311/AP.2018.58.0037. 